\title{
Papers
}

\section{Enzyme potentiated desensitisation in treatment of seasonal allergic rhinitis: double blind randomised controlled study}

Michael J Radcliffe, George T Lewith, Richard G Turner, Philip Prescott, Martin K Church, Stephen T Holgate

\author{
Abstract \\ Objective To assess the efficacy of enzyme \\ potentiated desensitisation in the treatment of severe \\ summer hay fever poorly controlled by \\ pharmacotherapy. \\ Design Double blind randomised placebo controlled \\ parallel group study. \\ Setting Hospital in Hampshire. \\ Participants 183 participants aged between 18 and \\ 64 with a history of severe summer hay fever for at \\ least two years; all were skin prick test positive to \\ timothy grass pollen. 90 randomised to active \\ treatment; 93 randomised to placebo.
}

Interventions Active treatment: two injections of enzyme potentiated desensitisation, given between eight and 11 weeks apart, each comprising 200 Fishman units of $\beta$ glucuronidase, $50 \mathrm{pg}$ 1,3cyclohexanediol, $50 \mathrm{ng}$ protamine sulphate, and a mixed inhaled allergen extract (pollen mixes for trees, grasses, and weeds; allergenic fungal spores; cat and dog danders; dust and storage mites) in a total volume of $0.05 \mathrm{ml}$ of buffered saline. Placebo: two injections of $0.05 \mathrm{ml}$ buffered saline solution.

Main outcome measures Proportion of problem-free days; global rhinoconjunctivitis quality of life scores assessed weekly during pollen season.

Results The active treatment group and the placebo group did not differ in the proportion of problem-free days, quality of life scores, symptom severity scores, change in quantitative skin prick provocation threshold, or change in conjunctival provocation threshold. No clinically significant adverse reactions occurred.

Conclusions Enzyme potentiated desensitisation showed no treatment effect in this study.

\section{Introduction}

Allergen specific immunotherapy has been in use for many years. A recent World Health Organization position paper concludes that this method relieves symptoms in allergic rhinitis. ${ }^{1}$ Prolonged clinical remission accompanied by a persistent alteration in immune reactivity may be induced by this method after many months or years of treatment. ${ }^{2}$ Use of allergen specific immunotherapy in the United Kingdom diminished considerably after a report by the Committee on Safety of Medicines in 1986 highlighted the risk of serious adverse reactions and death. ${ }^{3}$ The risks associated with the giving of large doses of allergens and the requirement for many doses of treatment have led to a search for adjuvant linked preparations that might be effective at much lower doses and need fewer treatments; one such method is enzyme potentiated desensitisation.

Although it has been in clinical use for a range of allergic conditions for more than 20 years, enzyme potentiated desensitisation was first proposed as a simple, effective, and safe low dose method of multiple pollen desensitisation for seasonal rhinitis in $1990 .^{4}$ Investigations, including dose finding studies, in mice and humans had previously established that $\beta$ glucuronidase possesses immune modulating properties in conjunction with certain activators and in the presence of small doses of allergen. ${ }^{5}{ }^{6}$ Between 300000 and 500000 doses have been given without serious reaction. If, in addition, the treatment could be shown to be effective against multiple allergens it might show considerable advantage over high dosage methods.

In the treatment of patients with pollen allergy six studies using a double blind placebo controlled design have shown that enzyme potentiated desensitisation by a single preseasonal injection is efficacious in reducing hay fever symptoms (table 1). Three of these studies involved participants with predominant grass pollen allergy, ${ }^{48}$ and a further three involved participants with a clinically relevant allergy to more than one type of pollen..$^{9-11}$ Each study found a significant difference in at least one out of three outcome measures (symptom scores, symptom-free days, and recourse to symptom relieving drugs), and one study found significant benefit across all three. We took the results of these previous investigations into account with a view to developing a more definitive and rigorous method. We aimed to test the hypothesis that in patients with seasonal rhinitis who are predominantly allergic to grass pollen, preseasonal enzyme potentiated desensitisation (two injections given eight weeks apart) can modify symptoms when compared with placebo.
School of Medicine, Infection

Inflammation and Repair Research Division, University of Southampton, Southampton General Hospital, Southampton SO16 6YD

Michael J Radcliffe visiting clinical research fellow

Martin K Church professor of

immunopharmacolog.

Stephen T Holgate

MRC clinical

professor of

immunopharmacology

School of Medicine,

Community

Clinical Sciences

Research Division,

University of

Southampton,

Royal South Hants

Hospital,

Southampton

SO14 OYG

George T Lewith

senior clinical

research fellow

North Hampshire

Hospital,

Basingstoke

RG24 9NA

Richard G Turner

associate specialist in

allergy

Faculty of

Mathematical

Studies, University

of Southampton,

Southampton

SO17 1BJ

Philip Prescott

professor of statistics

Correspondence to:

MJ Radcliffe

michael@

radcliffe.net

bmj.com 2003;327:251 
Table 1 Previous clinical trials of enzyme potentiated desensitisation in seasonal rhinitis

\begin{tabular}{|c|c|c|c|c|c|c|}
\hline \multirow[b]{2}{*}{ Reference } & \multirow[b]{2}{*}{ Pollens } & \multicolumn{2}{|c|}{ No of participants } & \multicolumn{3}{|c|}{ Efficacy } \\
\hline & & Active & Placebo & Symptoms & Symptom-free days & Rescue drugs \\
\hline Fell et al ${ }^{4}$ & Grass & 22 & 22 & NS & NS & $<0.02$ \\
\hline Longo et al ${ }^{7}$ & Grass & 9 & 7 & $<0.001$ & $<0.001$ & NS \\
\hline$\overline{\text { Di Stanislao et al }}{ }^{8}$ & Grass & 20 & 20 & NS & $<0.005$ & $<0.05$ \\
\hline$\overline{\text { Astarita et al }{ }^{9}}$ & Pellitory grass & 10 & 10 & $<0.001$ & - & - \\
\hline Angelini et $\mathrm{al}^{10}$ & Pellitory olive & 11 & 10 & 0.001 & $<0.001$ & $<0.001$ \\
\hline \multirow[t]{2}{*}{$\overline{\text { Caramia et al }{ }^{11}}$} & Grass & 8 & 8 & $<0.001$ & - & $<0.001$ \\
\hline & Dust mite & 27 & 27 & $<0.001$ & - & $<0.001$ \\
\hline
\end{tabular}

NS=not significant.

\section{Methods}

\section{Study population}

We carried out the study in Hampshire, England, and based it at the North Hampshire Hospital, Basingstoke. We recruited participants by advertisement in the local press and by referral from local general practitioners and community pharmacists. We asked any participant who satisfied basic eligibility criteria to attend for skin prick testing and rhinoscopic examination. We included patients if they were aged between 18 and 64, had a history of hay fever predominantly in June and July for two or more years, were poorly responsive to treatment with antihistamine and intranasal corticosteroid, and had a positive skin prick test (weal diameter $\geq 3 \mathrm{~mm}$ more than any measurable diameter of a negative control test) to timothy grass pollen (Phleum pratense, Soluprick ALK Abelló, Denmark). We excluded patients who gave a history of perennial rhinitis or asthma sufficient to warrant regular topical corticosteroid treatment, whose main rhinitis season was not June and July, who had received any immunotherapy within the previous 12 months, who had atopic dermatitis with any suspicion that the dermatitis was exacerbated during the pollen season, who gave a history of cardiovascular disease or other important medical condition, who showed an appreciable degree of nasal airway obstruction or polyp formation, or who were currently taking or had recently taken antidepressant or antipsychotic drugs.

\section{Assignment}

We randomised participants fulfilling the eligibility criteria to either active treatment or placebo immediately before administering the first of two injections given 8-11 weeks apart between January and March 2001. The statistician prepared a computer generated randomised treatment allocation sequence and retained it until all assessments and recordings had been completed. McEwen Laboratories prepared both the active and placebo treatment sets and numbered them according to the randomised sequence, holding the only copy of this sequence. We allocated participants the next set of paired treatment vials in the randomised sequence as they attended for their first injection. Neither the statistician nor any member of McEwen Laboratories played any part in the treatment of participants, and participants had no contact with any person who had access to the coded data.

\section{Intervention}

Each active injection was in the same form and dosage as had been given in the previously reported trials of enzyme potentiated desensitisation in hay fever. ${ }^{4-11}$ This consisted of 200 Fishman units of $\beta$ glucuronidase (derived from the mollusc Haliotis), $50 \mathrm{pg}$ of 1,3cyclohexanediol, $50 \mathrm{ng}$ of protamine sulphate, and mixed inhaled allergen extracts (pollen mixes for trees, grasses, and weeds; a mix of allergenic mould spores; cat and dog danders; dust and storage mites) in a total volume of $0.05 \mathrm{ml}$ of buffered saline. The buffered saline (which doubled as the placebo when injected alone in a volume of $0.05 \mathrm{ml}$ ) contained $\mathrm{MgSO}_{4} 0.06$ $\mathrm{g} / \mathrm{dl}$; sodium acetate $0.4 \mathrm{~g} / \mathrm{l} ; \mathrm{NaCl} 2.0 \mathrm{~g} / \mathrm{l} ; \mathrm{KCl} 4.0 \mathrm{~g} / \mathrm{l}$; and $\mathrm{CaCl}_{4} 1 \mathrm{~mol} / \mathrm{l}$ solution, $0.82 \mathrm{ml} / \mathrm{l}$, with $\mathrm{HCl}$ to adjust $\mathrm{pH}$ to 5.9. Participants avoided drugs suspected to interfere with desensitisation (for example, paracetamol, non-steroidal anti-inflammatory drugs, aspirin) and close contacts with other potent inhaled allergens (for example, cat fur or fungal spores) at the time of each dose.

\section{Masking}

Placebo and active treatments were both clear colourless solutions. Both may induce small areas of temporary local erythema and a brief stinging sensation after injection. In atopic people the active injection tends to induce a small (generally less than $3.0 \mathrm{~cm}$ diameter) localised weal and flare reaction after 15 to 20 minutes which is identical in appearance to that of a positive skin prick test. However, in clinical practice recipients invariably do not report itching when questioned at 30 minutes, in sharp contrast to the markedly pruritic weal and flare response of a positive skin prick test. We therefore accomplished blinding by applying a $4 \mathrm{~cm}$ diameter adhesive patch over the injection site until the next morning. Because we did not anticipate pruritus, we did not consider it necessary to use a solution of histamine as the placebo control. We chose buffered saline as placebo because, owing to its slightly acidic $\mathrm{pH}$, it is known to induce the brief stinging sensation characteristic of the active injection. If any local reaction beyond the adhesive patch or any systemic symptom occurred within one hour, this was recorded, but assuming no remedial action was needed (and in the event none was needed) such records were not made known to the investigators until the end of the study.

\section{Measurements and assessments}

Sensitivity to grass pollen

At the time of randomisation (October-December 2000) and again six to eight weeks post-treatment (April-May 2001) we performed incremental tests of sensitivity to grass pollen. We did quantitative skin prick tests with serially diluted allergen extracts in duplicate on the flexor surface of the forearm by using a parallel line method. ${ }^{12}$ Aquagen Timothy Grass extract at $100000 \mathrm{SQ}-\mathrm{U} / \mathrm{ml}$ (ALK Abelló) was the 
strongest testing solution, and we made serial (5x) dilutions with the Aquagen Diluent to produce five testing solutions at concentrations of 160, 800, 4000, 20000 , and $100000 \mathrm{SQ}-\mathrm{U} / \mathrm{ml}$.

We did conjunctival provocation tests by following the method of Möller et al. ${ }^{13}$ We used the same Aquagen Timothy Grass extract as above for the strongest testing solution and made serial $(5 x)$ dilutions with the Aquagen diluent to produce six testing solutions at concentrations of 32, 160, 800, 4000, 20000 , and 100000 $\mathrm{SQ}-\mathrm{U} / \mathrm{ml}$. We used Aquagen diluent as the negative control. We started by placing a single drop of diluent (control solution) into the right conjunctival sac. We then placed single drops of successively stronger solutions in the left conjunctival sac at 10 minute intervals, each step in the test sequence being contingent on a negative response in the immediately preceding test. We regarded any test as positive, and concluded the procedure, if after inspection for redness and inquiry about eye itch, eye weeping, eye burning, nose dripping, or nose blockage (scoring each as mild $=1$, moderate $=2$, and severe $=3$ ) a total score of 5 was reached.

\section{Symptoms and rescue drugs}

In the autumn before treatment we asked each participant to keep a baseline (out of season) diary of symptoms and all treatment used for two weeks during October, November, or December 2000. We did this both to establish the presence of any baseline rhinitis and as an aid to the optimisation of recording of symptoms during the grass pollen season. We then used precisely the same method as the main record of subjective severity of rhinitis during calendar weeks 20 to 31 inclusive of 2001 (14 May to 5 August inclusive).
During these two assessment periods we asked each participant to record a daily global rhinitis symptom score (using a seven point scale from no symptoms to very severe symptoms). In addition, at the end of each week we asked each participant to complete the mini rhinoconjunctivitis quality of life questionnaire (McMaster University). ${ }^{14}$ This questionnaire comprises 14 questions within five domains: activities, practical problems, nose symptoms, eye symptoms, and other symptoms. Each is assessed on a seven point severity scale.

During the same period we also asked participants to make a daily record (yes or no) of the freely allowed rescue drugs acrivastine (or own preferred antihistamine), cromoglicate nasal spray, and cromoglicate eye drops. Participants also recorded daily usage of the secondary rescue drugs beclometasone nasal spray and prednisolone, for which we arranged prescription if indicated after consultation with the study coordinator.

\section{Statistical analysis}

The primary outcome measures were proportion of problem-free days and post-treatment overall score for rhinoconjunctivitis related quality of life. We defined a symptom-free day as a day on which the symptom score was either 0 or 1 -that is, either no symptoms or very mild symptoms. Secondary outcome measures were change after treatment in daily hay fever symptom severity scores, quality of life scores, conjunctival provocation test score, and quantitative skin prick testing result.

An examination of previous studies showed that none was fully applicable to our study because of their limited size and differences in the prevailing pollens. In

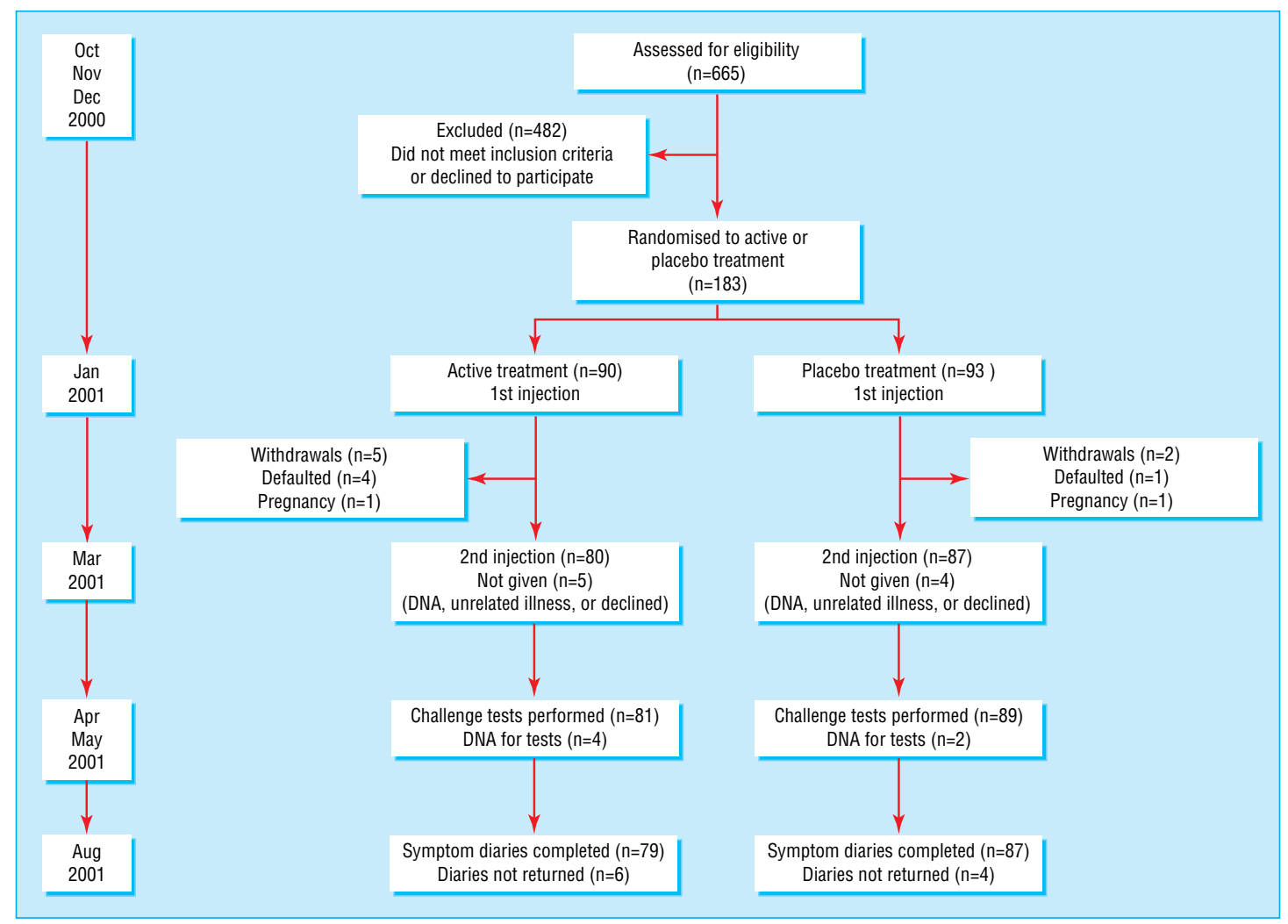

Fig 1 Flow diagram showing the numbers of participants at the different stages of the study. DNA=did not attend 
Table 2 Baseline data. Values are means (SDs) unless stated otherwise

\begin{tabular}{lcc} 
& Active $(\mathbf{n}=\mathbf{8 5})$ & Placebo $(\mathbf{n}=\mathbf{9 1})$ \\
\hline No of women & 41 & 46 \\
\hline Age of women (years) & $39.8(10.9)$ & $36.5(8.6)$ \\
\hline No of men & 44 & 45 \\
\hline Seve of men (years) & $38.6(11.4)$ & $37.1(10.5)$ \\
\hline Duration of rhinitis (years) & $3.34(0.70)$ & $3.44(0.50)$ \\
\hline Severity of asthma* & $22.67(11.46)$ & $19.94(10.31)$ \\
\hline Duration of asthma (years) & $1.55(0.68)$ & $1.34(0.60)$ \\
\hline $\begin{array}{l}\text { Conjunctival provocation test score (pretreatment } \\
\text { sensitivity to grass pollen) }\end{array}$ & $4.70(9.18)$ & $2.96(7.62)$ \\
\hline SPT positive to house dust mite (\%) & $2.81(0.84)$ & $2.75(0.90)$ \\
\hline SPT positive to pollens other than grass (\%) & $23(271)$ & \\
\hline
\end{tabular}

SPT=skin prick test

${ }^{*}$ Measured on a four point scale: $1=$ nil to $4=$ severe.

Table 3 Comparison of mean proportion of symptom-free days on scale (0-1) for two treatment groups by week of study

\begin{tabular}{lccr} 
Week & Placebo & Active & \multicolumn{1}{c}{ Difference $(\mathbf{9 5} \% \mathbf{C l})$} \\
\hline 1 & 0.686 & 0.738 & $-0.052(-0.168$ to 0.064$)$ \\
\hline 2 & 0.582 & 0.537 & $0.045(-0.087$ to 0.177$)$ \\
\hline 3 & 0.461 & 0.490 & $-0.029(-0.162$ to 0.104$)$ \\
\hline 5 & 0.305 & 0.297 & $0.008(-0.112$ to 0.128$)$ \\
\hline 6 & 0.251 & 0.220 & $0.031(-0.076$ to 0.138$)$ \\
\hline 7 & 0.189 & 0.172 & $0.017(-0.079$ to 0.113$)$ \\
\hline 8 & 0.230 & 0.230 & $0(-0.116$ to 0.116$)$ \\
\hline 10 & 0.379 & 0.329 & $0.050(-0.083$ to 0.183$)$ \\
\hline 11 & 0.526 & 0.489 & $0.037(-0.107$ to 0.181$)$ \\
\hline 12 & 0.656 & 0.637 & $0.019(-0.116$ to 0.154$)$ \\
\hline
\end{tabular}

addition, little information was available to assess the required sample sizes for differences between the quality of life assessments with the mini rhinoconjunctivitis quality of life questionnaire. For this reason, we based the initial power calculation on a comparison of the primary variable, the mean proportion of symptomfree days for the two treatment groups.

We compared treatment groups by using $t$ tests for means, non-parametric tests for medians, and $\chi^{2}$ tests for proportions, as appropriate. We looked for trends in the primary variables of symptom-free days, average symptom scores, and quality of life scores over the 12 weeks of the study by using repeated measures analysis of variance. We used analysis of covariance to compare these responses at week 6 with demographic and baseline variables as covariates. We used median tests to compare the eight symptom scores for side effects and $\chi^{2}$ squared tests to compare the size of swelling, duration of swelling, and itchiness for the two treatment groups after each injection.

\section{Results}

Of a total of 665 patients assessed for eligibility, we randomly assigned 183 participants -90 to the active treatment group and 93 to the placebo group. The remaining 482 patients either failed to meet the eligibility criteria or declined to participate before randomisation (fig 1). Withdrawals after randomisation (5/90 active, 2/93 control) left 176 participants (85 active, 91 control) for analysis. We included in the analysis and evaluation on an intention to treat basis those participants who failed to receive a second treatment injection (5/85 active, 4/91 control) together with participants who failed to complete the posttreatment challenge studies (4/85 active, 2/91 control) or the seasonal symptom diaries $(6 / 85$ active, $4 / 91$ control). In all, 166 participants provided symptom diaries for analysis.

The two groups of participants were well matched for age, sex, and duration and severity of rhinitis (table 2). Rather more participants in the active (31) than in the placebo (20) group had asthma. When we examined duration of asthma the difference was 1.7 years, with average durations of 4.70 years for the active group and 2.96 years for the placebo group. Assessment of severity of asthma showed a greater number of reports of mild (29 (34\%) $v 19(21 \%))$ or moderate $(9(11 \%) \cup 6(7 \%))$ asthma in the active treatment group. Baseline severity of rhinitis (recorded for two weeks during October to November 2000) did not differ between the two groups, whether assessed by symptom scores, quality of life scores, or proportion of symptom-free days. Baseline sensitivity to grass pollen as measured by the conjunctival provocation test did not differ. Rather more of the placebo group than the active group were sensitised to other pollens $(25 \% v$ $32 \%$ ), although the distribution of sensitivity to house dust mite (Dermatophagoides pteronyssinus) was similar between the groups ( $27 \%$ active $v 25 \%$ placebo). We made adjustments for any baseline differences in the comparative analyses.

We calculated the proportion of symptom-free days for each of the participants for each of the 12 weeks within the study period. The proportions did not differ between the two groups for any study week (table 3, fig 2). We calculated the overall quality of life score for each participant from the average of the scores of the 14 questions. The mean overall quality of life scores did not differ between the two groups for any study week (table 4, fig 3). In addition, we analysed adjusted average symptom scores for each of the 12 weeks of the study period by using an analysis of covariance taking age, sex, conjunctival provocation test score, severity of rhinitis history, severity of asthma history, and baseline proportion of symptom-free days as covariates (table 5, fig 4). No significant differences occurred.

We also did an analysis of covariance during week 6 , a week with a high grass pollen count during which rhinoconjunctivitis symptoms reached their peak. We compared the treatment groups for three outcome measures (proportion of symptom-free days, overall quality of life score, and average symptom score) allow-

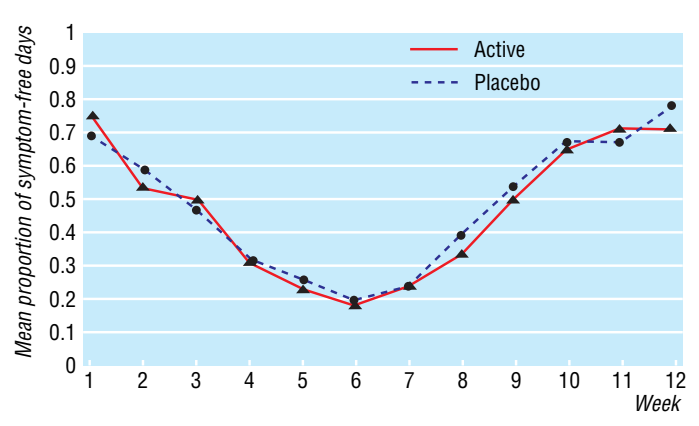

Fig 2 Proportion of symptom-free days each week by treatment group over the 12 weeks of the study 


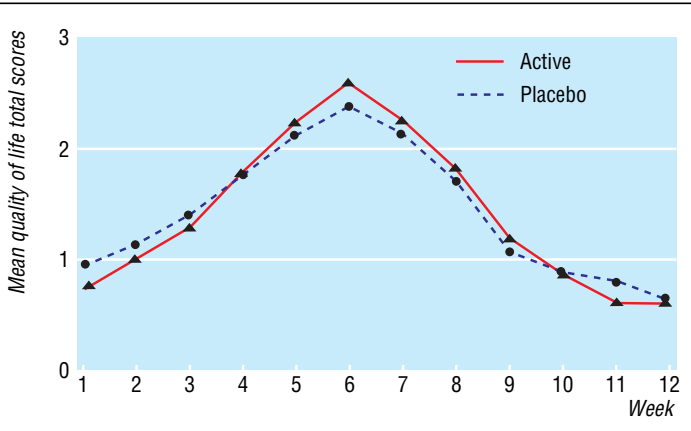

Fig 3 Mean overall quality of life score by treatment group for weeks 1 to 12 of the study

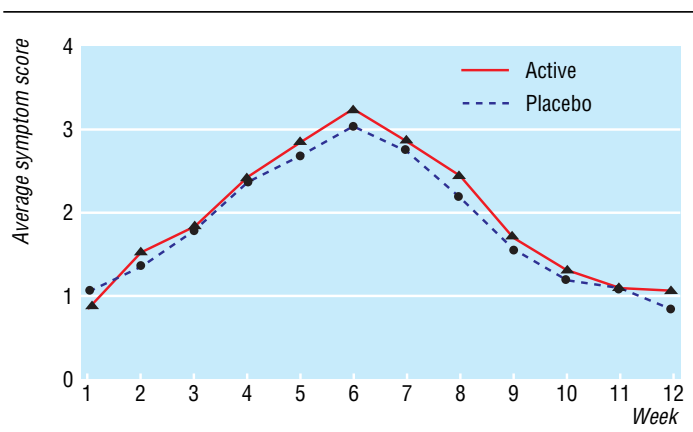

Fig 4 Means of the average symptom scores for weeks 1 to 12 for the two treatment groups, adjusted by analysis of covariance

ing for any demographic differences and any differences in the baseline assessments, including severity of rhinitis history and severity of asthma history. The adjusted treatment differences were not significant (table 6). We found no significant difference between the active and placebo groups when we examined for change in quantitative skin prick provocation threshold post-treatment, change in conjunctival provocation threshold post-treatment, or use of rescue drugs during week 6 , the peak symptom week.

Because little information had been available to us to assess the required sample sizes, we undertook a retrospective assessment of the sensitivity of the study. A difference in mean proportions of symptom-free days of 0.13 (that is, 13\%) could have been detected with samples of this size (approximately 80 in each group) with a power of $80 \%$ at $5 \%$ significance level. This assessment is based on the analysis of covariance adjusting for demographic and baseline differences. A similar retrospective analysis using quality of life data indicated that samples of the size used would have been able to detect, with $80 \%$ power at $5 \%$ significance level, a difference of 0.63 in the mean overall quality of life assessment using a scale from not troubled (0) to extremely troubled (6). This represents a difference of about $10 \%$ on the quality of life scale. Such a difference would have been clinically important, but the largest difference (placebo minus active) observed in the study was $-0.22(95 \%$ confidence interval -0.7 to 0.26$)$, which occurred during week 6 when the pollen count was at its highest level. This showed that the study was sufficiently powered to detect a clinically important difference in response to treatment, whether measured by proportion of symptom-free days or by quality of life scores.
Comparison of data recorded by participants relating to weals at the injection site showed significant differences between active and placebo groups for three measurements. Size of swelling $\left(\chi^{2}=98.4, \mathrm{df}=4\right.$, $\mathrm{P}<0.0005)$, duration of swelling $\left(\chi^{2}=98.2, \mathrm{df}=5\right.$, $\mathrm{P}<0.0005)$, and itchiness $\left(\chi^{2}=29.8, \mathrm{df}=1, \mathrm{P}<0.0005\right)$ were all greater after the first injection in actively treated participants than in controls. Sixty four $(72 \%)$ participants in the placebo group had no swelling, whereas $56(67 \%)$ of the active group had swellings of at least the size of a $5 \mathrm{p}$ coin. These swellings lasted for more than an hour in $71(84 \%)$ participants in the active group but in only $10(11 \%)$ of the control group. Only seven $(8 \%)$ of the placebo group experienced itchiness compared with 37 (44\%) of the active group. We found similar results for the second injection.

We analysed data for symptom scores within eight symptom domains recorded by participants for the seven days after each treatment injection for possible side effects of treatment. We saw significant differences only for skin symptoms. Although the vast majority of participants in both treatment groups said that they did not experience skin symptoms, more participants reported rash or itch and had higher score values in

Table 4 Comparison of mean overall quality of life score on scale $(0-6)$ for two treatment groups by week of study

\begin{tabular}{lccc} 
Week & Placebo & Active & Difference $(\mathbf{9 5} \% \mathbf{~ C l})$ \\
\hline 1 & 0.962 & 0.753 & $0.209(-0.102$ to 0.520$)$ \\
\hline 2 & 1.154 & 1.024 & $0.130(-0.203$ to 0.463$)$ \\
\hline 3 & 1.410 & 1.294 & $0.116(-0.246$ to 0.478$)$ \\
\hline 5 & 1.745 & 1.775 & $-0.030(-0.449$ to 0.388$)$ \\
\hline 6 & 2.117 & 2.232 & $-0.115(-0.596$ to 0.366$)$ \\
\hline 7 & 2.365 & 2.589 & $-0.224(-0.704$ to 0.256$)$ \\
\hline 9 & 2.126 & 2.244 & $-0.118(-0.595$ to 0.359$)$ \\
\hline 10 & 1.693 & 1.816 & $-0.123(-0.602$ to 0.356$)$ \\
\hline 11 & 1.072 & 1.191 & $-0.119(-0.510$ to 0.272$)$ \\
\hline 12 & 0.887 & 0.870 & $0.017(-0.321$ to 0.355$)$ \\
\hline
\end{tabular}

Table 5 Comparison of mean average symptom scores (on scale 0-6) for two treatment groups by week of study

\begin{tabular}{lccc} 
Week & Placebo & Active & Difference $\mathbf{( 9 5 \%}$ CI) \\
\hline 1 & 1.104 & 0.924 & $0.180(-0.164$ to 0.524$)$ \\
\hline 2 & 1.432 & 1.562 & $-0.130(-0.512$ to 0.252$)$ \\
\hline 4 & 1.855 & 1.824 & $0.031(-0.397$ to 0.459$)$ \\
\hline 5 & 2.411 & 2.445 & $-0.034(-0.468$ to 0.400$)$ \\
\hline 6 & 2.709 & 2.842 & $-0.133(-0.588$ to 0.322$)$ \\
\hline 7 & 3.048 & 3.207 & $-0.159(-0.611$ to 0.293$)$ \\
\hline 8 & 2.754 & 2.826 & $-0.072(-0.532$ to 0.388$)$ \\
\hline 9 & 2.203 & 2.359 & $-0.156(-0.631$ to 0.319$)$ \\
\hline 10 & 1.614 & 1.681 & $-0.067(-0.506$ to 0.372$)$ \\
\hline 11 & 1.250 & 1.300 & $-0.050(-0.439$ to 0.339$)$ \\
\hline 12 & 1.115 & 1.083 & $0.032(-0.360$ to 0.424$)$ \\
\hline
\end{tabular}

Table 6 Adjusted treatment group means and treatment differences for proportion of symptom-free days, overall quality of life score, and average symptom score in week 6 of the study

\begin{tabular}{|c|c|c|c|}
\hline \multirow[b]{2}{*}{ Variable } & \multicolumn{2}{|c|}{ Adjusted mean } & \multirow{2}{*}{$\begin{array}{l}\text { Placebo minus active } \\
(95 \% \mathrm{Cl})\end{array}$} \\
\hline & Placebo group & Active group & \\
\hline Proportion of symptom-free days & 0.20 & 0.17 & $0.03(-0.07$ to 0.13$)$ \\
\hline Overall quality of life score & 2.43 & 2.57 & $-0.14(-0.62$ to 0.34$)$ \\
\hline Average symptom score & 3.07 & 3.22 & $-0.15(-0.61$ to 0.32$)$ \\
\hline
\end{tabular}


the active treated group for both first and second injections. Tests for medians on both groups gave significant results for both the first and second injection. Analysis of post-treatment symptoms' scores for nose, throat, and sinus symptoms; eye symptoms; chest or breathing symptoms; pain symptoms; stomach or bowel symptoms; tiredness, weakness, or dizziness symptoms; or other symptoms for both first and second injections showed no significant differences between the active and placebo treated groups.

\section{Discussion}

The primary finding of this study was that two doses of enzyme potentiated desensitisation administered at an interval of eight to 11 weeks in the five months before the start of grass pollination was not efficacious in the treatment of pollen related seasonal rhinitis. We found no significant improvement in the treated group compared with the placebo group for symptom severity score, quality of life score, incremental provocation skin prick test, or conjunctival test. A small but significant increase in adverse events occurred for skin (rash and itch) symptoms after both the first and the second active injection. No difference occurred for any other adverse event recorded.

Although the two groups were well matched for most baseline characteristics, severity of asthma showed a difference that fell just short of statistical significance, and the active group had a slightly greater duration of asthma than the placebo group. However this difference does not seem to be associated with any difference in the incidence and severity of upper respiratory allergy between the groups, as neither history or duration of seasonal rhinitis nor severity of baseline rhinitis (as assessed by recordings made during the previous October to December) showed any difference. Neither did any difference occur when history of asthma was included as covariate within the adjusted analyses. It therefore seems unlikely that any difference in distribution of respiratory tract allergic disease between the groups would have had a major bearing on the outcome, although any effect there might have been would have tended to reduce apparent efficacy in the actively treated group.

We had not anticipated the difference in itchiness that we found between active and placebo injections. This is because an invariable observation of physicians using enzyme potentiated desensitisation is that patients report no itching when the weal and flare reaction is inspected 30 minutes after injection. It was for this reason that we did not choose a histamine containing solution as the placebo injection. The fact such a marked difference in reports of itchiness ( $44 \%$ active $v 8 \%$ placebo) occurred may therefore have introduced an element of loss of blinding between the treatments. Patients experiencing itch would have been likely to perceive this as a sign that they had received the active preparation rather than the placebo, having noted that itching was a feature of the positive, though not the negative, skin prick tests that had been carried out at the start of the study. Any effect that this loss of blinding might have had on the outcome would have tended to increase apparent efficacy.

We were also concerned to know why we encountered this unanticipated incidence of post-

\section{What is already known on this topic}

Enzyme potentiated desensitisation, a low dose multi-allergen immunotherapy method, has been in limited clinical use for hay fever in several countries for some years

Six small scale clinical studies have previously shown efficacy, although no large scale study has previously been undertaken

\section{What this study adds}

The enzyme potentiated desensitisation allergen immunotherapy method had no treatment effect in this study

The desensitising potency of the treatment might be subject to variation

injection pruritus. In a randomised controlled trial of enzyme potentiated desensitisation versus placebo in 20 patients with seasonal rhinitis, Astarita et al openly treated a further 10 patients with the allergen mixture alone devoid of the enzyme. ${ }^{9}$ Weal and flare skin response to the injection was invariably accompanied by pruritus in all 10 patients treated with the allergen mixture alone but in none of the 10 patients given the active treatment and in none of the subjects treated with placebo. This unexpected attenuation of weal and flare pruritus supports the suggestion that the enzymediol mixture does possess immune modulating properties. The apparent absence of this attenuation in $44 \%$ of the actively treated participants in our trial means that we cannot entirely exclude the possibility that the active material used, although stringently prepared to a good manufacturing practice standard, might have been subject to a loss of desensitising potency.

We considered other possible explanations for finding no treatment effect for enzyme potentiated desensitisation whereas six other placebo controlled studies have had positive findings, ${ }^{4-11}$ but we were unable to reach a conclusion. Our study population seems to have been of similar average age, although insufficient data were available from the other studies to allow us to establish if the participants were more severely affected or if they were more likely to be sensitive to multiple pollens.

In conclusion, allergen immunotherapy with enzyme potentiated desensitisation had no treatment effect in this rhinoconjunctivitis study involving a total of 183 volunteers. No significant differences occurred in the proportion of problem-free days, quality of life scores, symptom severity scores, change in quantitative skin prick provocation threshold, or change in conjunctival provocation threshold between the active and placebo treated groups. In the light of evidence of efficacy from six previous clinical trials of enzyme potentiated desensitisation in seasonal rhinitis, we searched for any reason why we were unable to detect a treatment effect but were unable to find one, except for the suggestion that the desensitising potency might be subject to variation. This possibility should be taken into account in the design of any future trial. In the meantime, the evidence of efficacy from the previous 
clinical trials of enzyme potentiated desensitisation in seasonal rhinitis should be viewed with caution.

We thank the hay fever patients from in and around Basingstoke who helped us with this study. We also thank Leonard McEwen for help with the study design and Elizabeth Juniper for her advice on the use of the mini rhinoconjunctivitis quality of life questionnaire and on questionnaire design generally. We also thank Jonathan Blanshard and Paul Spraggs, otorhinolaryngologists at the North Hampshire Hospital, for accommodating the study, organising the screening of the participants, and providing local medical supervision.

Contributors: MJR, GTL, RGT, and MKC designed the study with advice from STH. RGT organised the recruitment of volunteers and liaised with the collaborating consultants at the North Hampshire Hospital. Research nurses Frances Webley, Jackie Broomfield, and Lindsay Welch were responsible for the general administration of the study, the giving of treatment, and the collection and presentation of the data for analysis. PP analysed the data, with assistance in organisation and presentation from MJR, GTL, RGT, and MKC. MJR wrote the first draft of the paper, and all authors contributed to the final version. MJR will act as guarantor for the paper.

Funding: This study was funded partly by a grant from the NHS Executive (South East) Project Grant Scheme and partly by a grant from Great Universal Stores. Neither of these bodies played any part in the commissioning, design, or execution of the study. The views expressed are those of the authors. McEwen Laboratories supplied the enzyme potentiated desensitisation treatment and also funded the provision of the rescue drugs. Leonard McEwen of McEwen Laboratories gave advice about the study design and was responsible for preparing and supplying the active and placebo treatment injection sets according to the randomisation series provided by the statistician. Neither he nor any member of McEwen Laboratories Ltd was involved directly in the execution of the trial.

Competing interests: MJR was funded by a grant from McEwen Laboratories and has received fees for lecturing and consulting from the same source. GTL is funded by a grant from the Maurice Laing Foundation. STH has consultancies with several pharmaceutical companies in relation to asthma research and receives grants and support for clinical trial work from various companies; none of these represents a competing interest with the work described in this paper.

Ethical approval: Southampton and South West Hampshire local research ethics committee.

1 Bousquet J, Lockey RF, Malling H-J. Allergen immunotherapy: therapeutic vaccines for allergic diseases. Allergy 1998;53(suppl 44):1-42

2 Durham SR, Walker SM, Varga EM, Jacobsen MR, O'Brien F, Noble W, et Durham SR, Walker SM, Varga EM, Jacobsen MR, O'Brien F, Noble W, et
al. Long-term clinical efficacy of grass-pollen immunotherapy. $N$ Engl J Med 1999;341:468-75.

3 Committee on Safety of Medicines. CSM update: desensitising vaccines. BMJ 1986;293:948.

4 Fell P, Brostoff J. Single dose desensitisation for summer hay fever. Eur J Clin Pharmacol 1990;38:77-9.

5 McEwen LM. Enzyme-potentiated hyposensitization: effects of glucose, glucosamine, $\mathrm{N}$-acetylamino-sugars and gelatin on the ability of $\beta$-olucuronidase to block the anamnestic response to antigen in mice Ann Allergy 1973:31:79-83.

6 McEwen LM, Nicholson, M. Kitchen I, White S. Enzyme-potentiated hyposensitization: III control by sugars and diols of the immunological effect of beta glucuronidase in mice and patients with hay fever. Ann Allergy 1973;31:543-50

7 Longo G. Poli F. Bertoli G. Efficacia clinica di un nuovo trattemento iposensibilizzante, EPD (enzyme potentiated desensitisation) nella terapia della pollinosi. Reforma Medica 1992;107:171-6.

8 Di Stanislao C, Di Berardino L, Bianchi I, Bologna G. A double-blind, placebo-controlled study of preventive immunotherapy with EPD, in the treatment of seasonal allergic disease. Allerg Immunol (Paris) 1997;29: $39-42$.

9 Astarita C, Scala, G, Sproviero S, Franzese A. Effects of enzymepotentiated desensitisation in the treatment of pollinosis: a double-blind potentiated desensitisation in the tleatment of pollinosis: a double-blind

10 Angelini G, Curatoli G, D'Argento V, Vena GA. Pollinosis: una nuova Angelini G, Curatoli G, D'Argento V, Vena GA. Pollinosis:
metodica di immunoterapia. Medit J Surg Med 1993:253-6.

11 Caramia G, Franceschini F, Cimarelli ZA, Ciucchi MS, Gagliardini R, Ruffini E. The efficacy of EPD, a new immunotherapy, in the treatment of allergic diseases in children. Allerg Immunol (Paris) 1996;28:308-10.

12 Malling H-J. Proposed guidelines for quantitative skin prick test procedures to determine the biological activity of allergenic extracts using parallel line assay. Allergy 1987;42:391-4.

13 Möller C, Björkstén B, Nilsson G, Dreborg S. The precision of the conjunctival provocation test. Allergy 1984;39:37-41.

14 Juniper EF, Thompson AK, Ferrie PJ, Roberts JN. Development and validation of the mini rhinoconjunctivitis quality of life questionnaire. Clin Exp Allergy 2000;30:132-40.

(Accepted 6 May 2003) 